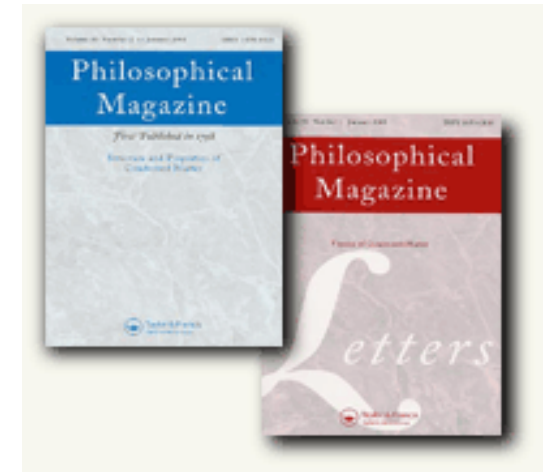

\title{
The temperature dependence of heavy-ion damage in iron: a microstructural transition at elevated temperatures
}

\begin{tabular}{|c|c|}
\hline Journal: & Philosophical Magazine \& Philosophical Magazine Letters \\
\hline Manuscript ID: & TPHM-09-Jul-0317.R1 \\
\hline Journal Selection: & Philosophical Magazine \\
\hline $\begin{array}{r}\text { Date Submitted by the } \\
\text { Author: }\end{array}$ & 15-Oct-2009 \\
\hline Complete List of Authors: & $\begin{array}{l}\text { Yao, Zhongwen; University of Oxford, Materials } \\
\text { Jenkins, Mike; University of Oxford, Materials } \\
\text { Hernández-Mayoral, Mercedes; CIEMAT, Division of Materials } \\
\text { Kirk, Mark; Argonne National Laboratory, Materials Science Division }\end{array}$ \\
\hline Keywords: & $\begin{array}{l}\text { radiation damage, in-situ electron microscopy, defect analysis, } \\
\text { microstructural characterization }\end{array}$ \\
\hline \multicolumn{2}{|l|}{ Keywords (user supplied): } \\
\hline \multicolumn{2}{|c|}{$\begin{array}{l}\text { Note: The following files were submitted by the author for peer review, but cannot be converted } \\
\text { to PDF. You must view these files (e.g. movies) online. }\end{array}$} \\
\hline $\begin{array}{l}\text { video } 1 . \mathrm{mov} \\
\text { Video } 2 . \mathrm{mov} \\
\text { Video } 3 . \mathrm{mov} \\
\text { Video } 4 . \mathrm{mov} \\
\text { Video } 5 . \mathrm{mov} \\
\text { Video } 6 . \mathrm{mov}\end{array}$ & \\
\hline
\end{tabular}




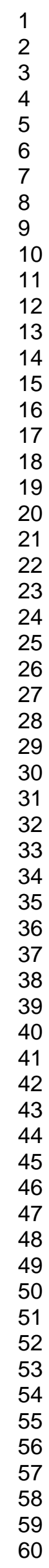

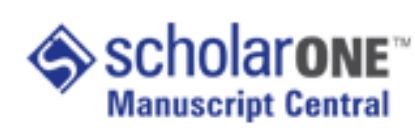

http://mc.manuscriptcentral.com/pm-pml 


\title{
The temperature dependence of heavy-ion damage in iron: a microstructural transition at elevated temperatures
}

\author{
Z. Yao ${ }^{*}$, M. L. Jenkins s ${ }^{* 1}$, M. Hernández-Mayoral ${ }^{* *}$ and M. A. Kirk ${ }^{* * *}$ \\ * Department of Materials, University of Oxford, Parks Rd., OX1 3PH \\ ** Division of Materials, CIEMAT Avenida Complutense, 22, 28040-Madrid \\ **** Materials Science Division, Argonne National Laboratory, Argonne, IL 60439
}

\footnotetext{
${ }^{1}$ Corresponding author: Email: mike.jenkins@materials.ox.ac.uk
} 


\section{Introduction}

It has been long known that the mechanical properties of steels start to degrade at temperatures above about $500^{\circ} \mathrm{C}$ - a relatively low temperature $\left(0.42 T_{m}\right)$. According to recent theoretical calculations [1,2], a possible cause of this is an elastic instability, driven by spin fluctuations. This results in a large reduction in the shear stiffness constant $\mathrm{C}^{\prime}=\left(\mathrm{C}_{11}-\mathrm{C}_{12}\right) / 2$ at the $\alpha \rightarrow \gamma$ phase transition temperature of $912^{\circ} \mathrm{C}$, although effects on mechanical properties are manifest at temperatures well below this. The same theory predicts that dislocation loops with Burgers vector $\mathbf{b}=<100>$ will become relatively more stable with respect to loops with $\mathbf{b}=1 / 2<111>$ with increasing temperature.

Deleted: a

Deleted: $a / 2$

In previous papers we have described in-situ ion-irradiation experiments which followed the evolution of microstructures in thin foils of pure iron $(\mathrm{Fe})$ and $\mathrm{FeCr}$ alloys at irradiation temperatures $\mathrm{T}_{\text {irr }} \leq 300^{\circ} \mathrm{C}[3-5]$ and at $500^{\circ} \mathrm{C}$ [5]. These experiments provided

| support for the view that dislocation loops with $\mathbf{b}=\leq 100>$ increase in stability with temperature. For $\mathrm{T}_{\text {irr }} \leq 300^{\circ} \mathrm{C}$, the microstructures both in pure $\mathrm{Fe}$ and in $\mathrm{FeCr}$ alloys irradiated with $150 \mathrm{keV} \mathrm{Fe}^{+}$ions were dominated by interstitial loops with Burgers

$\mid$ vectors $\mathbf{b}=1 / 2<111>$. These loops were frequently round or of irregular shape and had significant shear components, and sometimes coalesced into large finger-shaped loops. However, in the same materials irradiated at $500^{\circ} \mathrm{C}$, only rectilinear pure-edge interstitial | loops with $\mathbf{b}=<100>$ loops were present.

Deleted: a

Deleted: $a / 2$

Deleted:

In the present paper this transition in microstructures is explored in more detail in pure Fe. All images and videos included in this paper were recorded under weak-beam diffraction conditions [6]. The weak-beam method of transmission electron microscopy has become an indispensable tool in this area of research (for a review giving full experimental details, see ref. [7]).

\section{Experimental method}

The materials were the same as those investigated previously (annealed ultra-high purity polycrystalline $\mathrm{Fe}$ and a somewhat less pure $\mathrm{Fe}$ single crystal - see ref. [3] for details, Full details of specimen preparation and irradiation in the Argonne-IVEM Tandem Facility have been given in a previous paper [3]. Briefly, specimens were electro-polished with minimum exposure to air and introduced immediately into an Hitachi H-9000NAR transmission electron microscope interfaced to an ion implanter. They were then irradiated with $150 \mathrm{keV} \mathrm{Fe}^{+}$self ions at temperatures ranging $400^{\circ} \mathrm{C}$ to $500{ }^{\circ} \mathrm{C}$, with an estimated accuracy of $\pm 10^{\circ} \mathrm{C}$. We estimate that for this irradiation condition the peak of the damage occurs at a depth of about $28 \mathrm{~nm}$ [3]. The regions of foil investigated in the TEM were typically of thickness $30-40 \mathrm{~nm}$, so the damage peak was close to the foil centre. We found in our previous work that in such foils small $1 / 2<111>$ dislocation loops were very mobile, and in some foil orientations some of these loops were lost by glide to the foil surfaces under the influence of surface image forces [3-5]. For this reason the single-crystal Fe used in some of the present experiments was spark-cut into slices parallel to the (110) plane in order to obtain TEM specimens with a [110] foil normal. In 
foils of this orientation some loop variants have their Burgers vectors in or close to the foil plane, and so cannot easily be lost by glide (see section 3.3 for details).

The evolution of radiation damage was followed by dynamic TEM observations under weak-beam diffraction conditions to doses $\leq 2 \times 10^{19}$ ions $\mathrm{m}^{-2}(\sim 13 \mathrm{dpa})$. In most of the present experiments irradiations were terminated at a dose of 2 or $3 \times 10^{18}$ ions $\mathrm{m}^{-2}$ ( 1.3-2 dpa). Irradiations were paused from time to time to allow detailed characterization of microstructures using standard diffraction-contrast techniques [7]. Similar detailed characterization was performed at the end of the irradiation after specimens had cooled to room temperature.

\section{Results \\ $3.1 \quad T_{\text {irr }}=400^{\circ} \mathrm{C}$}

At doses $<10^{18}$ ions $\mathrm{m}^{-2}$, the initial damage microstructure was similar to that seen in previous experiments at $300^{\circ} \mathrm{C}$. Small dislocation loops, visible as white dots of diameter less than about $5 \mathrm{~nm}$ in weak-beam images, appeared within a timescale of a few video frames. Most of these loops were extremely mobile, making large and frequent "hops" in $\mid<111>$ directions, consistent with $1 / 2<111>$ Burgers vectors. The frequencies and amplitudes of hops were much larger than those seen in the same material at $300^{\circ} \mathrm{C}$ [3] or in the 1-D diffusion of loops seen in similar material under electron irradiation at temperatures $<400^{\circ} \mathrm{C}[8]$. As the irradiation progressed, loops were seen to interact elastically, making coordinated hops and occasionally coalescing into larger loops. This behaviour is illustrated in video 1 , which shows damage development under ion irradiation over a dose range $0-5 \times 10^{17}$ ions $\mathrm{m}^{-2}$. The coalescence after irradiation of a

| string of three $1 / 2<111>$ loops into a larger, but still mobile $1 / 2<111>$ loop which then rotates on its glide cylinder is shown in video 2 , with stills from this video in figure 1 . By a dose of $2 \times 10^{18}$ ions $\mathrm{m}^{-2}(\sim 1.3 \mathrm{dpa})$, elastic interactions led to the formation of chains of large $(30-50 \mathrm{~nm})$, round loops in thicker areas, reminiscent of those seen at lower irradiation temperatures [3-5] but on a larger scale. The formation of loop chains under irradiation may be viewed dynamically in video 3 .

In video 3 , it may be seen that a number of loops appeared more gradually and | were immobile, and it was surmised that these had $<100>$ Burgers vectors. A postirradiation Burgers vector analysis was carried out at the final dose of $2 \times 10^{18}$ ions $^{-2}$, and selected micrographs from this experiment are shown in figure 2 . The analysis confirmed that both $1 / 2<111>$ and $<100>$ loops had formed. Large $(30-50 \mathrm{~nm})$ loops had Burgers vectors $\mathbf{b}=1 / 2[1] 1]$ or $\mathbf{b}=1 / 2[111]$ (and so were out of contrast in figure $2 \mathrm{~d}$ ) or $\mathbf{b}=[001]$ (and so were out of contrast in figure $2 \mathrm{a}$ ). Interestingly, no large loops of the other variants were seen in this area. Small $(\sim 10 \mathrm{~nm})$ loops of each type and variant were also | present. The number density of $<100>$ loops was larger than that of $1 / 2<111>$ loops, but on average they were much smaller, so that a majority of point defects was contained in $\mid \underline{1} / 2<111>$ loops. This will be quantified and discussed later. Stereo experiments showed that large loops were localized towards the foil centre, whilst smaller loops were distributed throughout the foil, regardless of their Burgers vectors. This may be seen in 
video 4, which shows a tilt series constructed using EM3D tomography software from a set of 7 stereo images taken over a tilt range of $\sim 35^{\circ}$ with $\mathbf{g}=002$.

By inspection of figure 2 it may be seen that the large [001] loops are of pureedge type. The foil normal in this micrograph is [100] and edge-on loops with $\mathbf{b}=[001]$ are seen to lie perpendicular to the diffraction vector $\mathbf{g}=00 \overline{2}$ in figure $2 \mathrm{c}$. Similar pure$\mid$ edge $<100>$ loops were found in our previous work at $\mathrm{T}_{\text {irr }}=500^{\circ} \mathrm{C}$, where their nature was determined to be interstitial [5]. Micrographs taken at other orientations showed that $\mid<100>$ loops larger than about 20nm were rectilinear with edges along $<100>$ directions. Smaller ones looked more rounded. The detailed shape of loops is discussed in a separate paper [9].

The $1 / 2<111>$ loops are non-edge. A full Burgers vector analysis (carried out using the reflections available at both the [110] and [100] poles) showed that the predominant Burgers vector of the large loops in the area of foil shown in figure $3 \mathrm{a}$ was

$1 / 2[\overline{1} 11]$. The habit plane of these loops was found by tilting the foil from pole [110] $\rightarrow$ $[310] \rightarrow$ [100], whilst maintaining the same weak-beam diffraction condition with $\mathbf{g}=002$. The loops appear edge-on at the [310] pole, imaging as lines lying perpendicular to the [132] direction (figure 3a). They therefore lie on or close to the (132) plane, so that the angle between the loop normal $\mathbf{n}$ and $\mathbf{b}$ is about $22^{\circ}$. Figures $3 \mathrm{~b}$ and $3 c$ show experimental images of two loops recorded close to the [110] and [310] poles respectively. Image simulations using the program TEMACI [10] for circular loops | with $\mathbf{b}=1 / 2[111]$ with a $(\overline{1} 32)$ habit plane are inset at the lower left of each figure. The good match between experimental and simulated images confirms our interpretation. In | our previous experiments in UHP-Fe at $300^{\circ} \mathrm{C}$ the large $1 / 2<111>$ "finger" loops which formed at high doses were also found to have significant shear components and were also found to be interstitial [4].

\section{$3.2 T_{i r r}=450^{\circ} \mathrm{C}$}

In an experiment carried out at $\mathrm{T}_{\mathrm{irr}}=450^{\circ} \mathrm{C}$ on an UHP Fe foil oriented about $20^{\circ}$ from [111], early stages in damage development were similar to those seen at $400^{\circ} \mathrm{C}$, except that larger-scale microstructures appeared more slowly. Small loops were seen early in the irradiation, and were extremely mobile, and were frequently lost from the foil. As the dose increased, again chains of loops formed, interacting elastically. By a dose of $3 \mathrm{x}$ $10^{18}$ ions $\mathrm{m}^{-2}$, long lines of large $1 / 2<111>$ loops had formed in thicker regions, all with the same Burgers vector, and looking similar to the microstructure examined in detail at $400^{\circ} \mathrm{C}$ (figure $4 \mathrm{a}$ ). In an adjacent grain tilted close to [100], regions were found where | large loops of both $<100>$ and $1 / 2<111>$ types were present (figure $4 \mathrm{~b}$ ), although $<100>$ loops were in a preponderance. In other regions of this grain large numbers of edge-on $\mid<100>$ loops were visible (figure $4 \mathrm{c}$ ). The absence of $1 / 2<111>$ loops in figure $4 \mathrm{c}$ may well be a contrast effect: the large loops in figure $4 \mathrm{~b}$ are visible in $\mathbf{g}=01 \overline{1}$ and so have either $\mathbf{b}=1 / 2[1 \overline{1} 1]$ or $\mathbf{b}=1 / 2[11 \overline{1}]$, but loops with these Burgers vectors would be out of contrast in figure $4 \mathrm{c}$ which was taken in $\mathbf{g}=011$. The average sizes of $<100>$ loops were significantly larger than at $400^{\circ} \mathrm{C}$, and a majority of point-defects was now contained in

\begin{tabular}{|c|}
\hline Deleted: $\mathrm{a} / 2$ \\
\hline Deleted: a \\
\hline Deleted: $\mathrm{a} / 2$ \\
\hline Deleted: a \\
\hline Deleted: a \\
\hline Deleted: a/2 \\
\hline Deleted: $a / 2$ \\
\hline Deleted: $a / 2$ \\
\hline Deleted: a \\
\hline
\end{tabular}


such loops, see below. This temperature seems to mark a transition from a mostly

$\mid \underline{1 / 2}<111>$ microstructure to a microstructure dominated by $<100>$ loops.

\section{$3.3 \quad T_{i r r}=460^{\circ} \mathrm{C}-500^{\circ} \mathrm{C}$}

| At $500^{\circ} \mathrm{C}$, we found in our previous work that only $<100>$ loops formed in [100] foils [5]. These loops appeared slowly over several minutes, and were immobile. Figure 5 a shows the microstructure at a dose of $3 \times 10^{18}$ ions $\mathrm{m}^{-2}$, where loops of sizes up to about $50 \mathrm{~nm}$ were present but well separated. As these loops grew under continuing irradiation, they coalesced with neighbouring loops with the same Burgers vector until they impinged on loops of the other variants, forming the microstructure seen in figure $5 \mathrm{~b}$. In this figure, loops belonging to all three $<100>$ variants can be seen. Two variants, with $\mathbf{b}=[001]$ and $\mathbf{b}=[010]$, appear edge-on, forming a quasi-regular ladder-like structure. Loops of the third variant, with $\mathbf{b}=[100]$, lie in the plane of the foil and are faintly visible in residual $\mathbf{g . b} \times \mathbf{u}$ contrast. Occasionally during irradiation loops with this Burgers vector were | suddenly lost from the foil by glide, see video 5, demonstrating that $<100>$ loops are not intrinsically sessile.

In foils with normal [100], all variants of $1 / 2<111>$ loops have a component of Burgers vector pointing towards the surface. Since $1 / 2<111>$ loops are highly mobile at $500^{\circ} \mathrm{C}$, the possibility exists that such loops do form, but are lost by glide to the surface $\mid$ before they are seen. Total loss of $1 / 2<111>$ loops in (100) foils is known to occur in ionirradiated Mo [11]. In order to exclude this possibility, the following experiments were carried out in single-crystal foils with orientation close to [110]. In such foils, loops with

$\mid \mathbf{b}=1 / 2[111]$ and $\mathbf{b}=1 / 2[1 \overline{1} 1]$ have little or no component of Burgers vector towards the surface, and so cannot easily be lost by glide.

First a foil was irradiated to a moderate dose $\left(1 \times 10^{18} \mathrm{~m}^{-2}\right)$ at $500^{\circ} \mathrm{C}$. Sessile loops with $\mathbf{b}=\left\langle 100>\right.$ were seen to form, but no loops with $\mathbf{b}=1 / 2<111>$ loops were found ${ }^{2}$. A further irradiation of the same foil was then performed at $482^{\circ} \mathrm{C}$. A few small $1 / 2<111>$ loops were produced in the field of view of the CCD camera. All remained in the foil and hopped along $<111>$ directions in the plane of the foil. Soon after irradiation, none of $\mid$ these $1 / 2<111>$ loops could be found. It was not clear by which mechanism they had disappeared.

A second foil was irradiated at $465^{\circ} \mathrm{C}$. Video 6 shows this specimen under ion irradiation, and figure 6 shows a series of stills from this video. The video shows directly the fate of $1 / 2<111>$ loops at elevated temperatures. In the area of observation are some easily-recognized, large, sessile, near edge-on $<100>$ loops and two small $(\sim 5 \mathrm{~nm})$ $1 / 2<111>$ loops, located on either side of a larger $(\sim 50 \mathrm{~nm})<100>$ loop (arrowed in figure 6). At first, the two $123<111>$ loops hopped parallel to their Burgers vector. Their glide cylinders did not intersect the $<100>$ loop. However, within a minute both $1 / 2<111>$ loops had moved towards the $<100>$ loop, this motion involving sideways steps perpendicular to their glide cylinders. On reaching the $<100>$ loop they were subsumed, causing the

\footnotetext{
${ }^{2} \mathrm{We}$ have recently found the same result in a [110] $\mathrm{Fe}-\mathrm{C}$ alloy irradiated at $500^{\circ} \mathrm{C}$ under the same conditions.
}

\begin{tabular}{|l|}
\hline Deleted: a \\
\hline Deleted: a \\
\hline Deleted: 2
\end{tabular}

Deleted: a

Deleted: a

Deleted: a

Deleted: a

Deleted: a

Deleted: a

\begin{tabular}{l} 
Deleted: $\mathrm{a} / 2$ \\
Deleted: $\mathrm{a} / 2$ \\
Deleted: expected to be \\
Deleted: $\mathrm{a} / 2$ \\
\hline
\end{tabular}

Deleted: a/2

Deleted: a/2

Deleted: a

Deleted: a/2

Deleted: a/2

Deleted: a/2

\begin{tabular}{|l|} 
Deleted: $a / 2$ \\
Deleted: $a$ \\
Deleted: $a / 2$ \\
Deleted: a \\
Deleted: a/2 \\
Deleted: a \\
Deleted: a/2 $a$ \\
\hline
\end{tabular}


$<100>$ loop to grow. The increase in size of the $<100>$ loop indicates that the two

$1 / 2<111>$ loops which it had absorbed had the same nature as the $<100>$ loop itself, i.e. all were interstitial.

\section{Discussion}

| The occurrence of $<100>$ loops in Fe irradiated at high temperature has been known since the pioneering work of Masters [12], who carried out thin-foil irradiation experiments similar to our own. Masters found exclusively $<100>$ loops of interstitial nature in pure $\mathrm{Fe}$ irradiated with $150 \mathrm{keV} \mathrm{Fe}^{+}$ions at $550^{\circ} \mathrm{C}$. Subsequently $\leq 100>$ loops, or a mixture of $<100>$ and $1 / 2<111>$ loops, have been found in many other elevated-temperature experiments in ferritic materials. These include, for example, experiments by Konobeev

I et al [13] who found $<100>$ interstitial loops (as well as voids) in $\mathrm{Fe}$ and $\mathrm{Fe} 0-18 \% \mathrm{Cr}$ irradiated with fast neutrons to doses up to $25.8 \mathrm{dpa}$ at $400^{\circ} \mathrm{C}$. As a further example,

| Gelles [14] also found that $<100>$ loops predominated in $\mathrm{Fe} 3 \% \mathrm{Cr}$ alloys irradiated with neutrons to $\sim 20 \mathrm{dpa}$ at temperatures between $400^{\circ} \mathrm{C}$ and $450^{\circ} \mathrm{C}$, although a mixture of the two loop types was found in higher $\mathrm{Cr}$ alloys. In our own recent experiments in $\mathrm{Fe}$ irradiated in the bulk with $0.5-3 \mathrm{MeV} \mathrm{Fe}^{+}$ions to $\sim 10 \mathrm{dpa}$ at $500^{\circ} \mathrm{C}$, we also found almost exclusively interstitial $<100>$ loops, whilst at $300^{\circ} \mathrm{C}$ a mixture of $<100>$ and $1 / 2<111>$ loops was present. In FeCr alloys, however, both loop types were present at $500^{\circ} \mathrm{C}[15]$. In these and other experiments there does seem a clear pattern for $<100>$ loops to predominate in pure $\mathrm{Fe}$ at irradiation temperatures $\mathrm{T}_{\mathrm{irr}} \geq 400^{\circ} \mathrm{C}$. In contrast, in $\mathrm{Fe}$ irradiated at $60^{\circ} \mathrm{C}$ with neutrons, only $1 / 2<111>$ loops were identified, again of interstitial nature [16]. The only examples we know of $\leqslant 100>$ loops in low-temperature irradiations are found in $\mathrm{Fe}$ irradiated with $\mathrm{W}^{+}$ions at room temperature [17] and with high doses of self-ions [18], and in these cases loops were considered to have formed by a process of cascade collapse and the loop nature was vacancy.

| Our present work has provided further evidence that,$<100>$ loops become increasingly dominant in $\mathrm{Fe}$ with increasing irradiation temperature. In figure 7 we have made an attempt to quantify the proportions of interstitials contained in $<100>$ and $1 / 2<111>$ at various temperatures. This figure was constructed by measuring the size distributions and number densities of the two types of loops at different irradiation temperatures. At $\mathrm{T}_{\mathrm{irr}}=400^{\circ} \mathrm{C}$, about $80 \%$ of loops were of the $<100>$ type, but their mean size was only about a third that of the $1 / 2<111>$ loops, and so the fraction of interstitials contained in loops of the two types was comparable. At $\mathrm{T}_{\text {irr }}=450^{\circ} \mathrm{C}$, the majority of interstitials was contained in $<100>$ loops, but large $1 / 2<111>$ round loops were still present in some areas. At $\mathrm{T}_{\text {irr }} \geq 492^{\circ} \mathrm{C}$, no $<111>$ loops were seen during ion irradiation, whereas $<100>$ loops formed and grew. As a rough estimate, the total number of interstitials contained in $<100>$ loops at $500^{\circ} \mathrm{C}$ was comparable with the number of interstitials contained in loops at $300^{\circ} \mathrm{C}$, for the same irradiation dose. No correction has | been made in figure 7 for loss of mobile $1 / 2<111>$ loops to the surface, nor for the effects of foil orientation and thickness, nor for the variability in loop types from area to area. Discussions of these effects may be found in our previous papers [3,5]. Their neglect is | likely to lead to an underestimate of the number of interstitials in $1 / 2 \leq 111>$ loops at all temperatures, but we believe that the trends shown are real.

\begin{tabular}{|l|}
\hline Deleted: a \\
\hline Deleted: a \\
\hline Deleted: $\mathrm{a} / 2$ \\
\hline Deleted: $\mathrm{a}$ \\
\hline
\end{tabular}

Deleted: a

\begin{tabular}{|l|}
\hline Deleted: a \\
\hline Deleted: a \\
\hline Deleted: a \\
\hline Deleted: $a / 2$ \\
\hline Deleted: $a$ \\
\hline
\end{tabular}

Deleted: a

\begin{tabular}{l} 
Deleted: $a$ \\
\hline Deleted: $a$ \\
\hline Deleted: $a / 2$ \\
Deleted: $a$ \\
\hline Deleted: $a / 2$ \\
\hline
\end{tabular}

Deleted: a

Deleted: a

Deleted: a/2

Deleted: a

Deleted: a/2

\begin{tabular}{|l|}
\hline Deleted: a \\
\hline Deleted: a/2 \\
Deleted: a \\
Deleted: a \\
Deleted: $a$ \\
\hline
\end{tabular}

Deleted: a/2 
In parallel with our experimental work, Dudarev et al. [1,2] developed methods of calculating the self-energy of loops of different Burgers vectors and morphologies as a function of temperature. As mentioned in the introduction, they found that the reduction in the shear stiffness constant $C^{\prime}$ with increasing temperature caused a profound effect on the anisotropic elastic self-energies of dislocations in $\mathrm{Fe}$ and on the relative stability of $<100>$ and $1 / 2<111>$ dislocation loops. For example, for loops of perimeter $\mathrm{P}=10 \mathrm{~nm}$, hexagonal, prismatic pure-edge dislocation loops with Burgers vector $1 / 2<111>$ were found to be unconditionally stable at temperatures $\mathrm{T}<350^{\circ} \mathrm{C}$, whereas square $\left.<100\right\rangle$ pure-edge loops were unconditionally stable for $\mathrm{T}>550^{\circ} \mathrm{C}$. In the intermediate | temperature region, $350^{\circ} \mathrm{C}<\mathrm{T}<550^{\circ} \mathrm{C}$, loops of this size with $\mathbf{b}=1 / 2<111>$ and edges along $<\overline{1} 10>$ directions were thermodynamically unstable and could lower their free energy either by changing shape (with edges along $<11 \overline{2}>$ directions) or by transforming | to $<100>$ loops. Dudarev et al. [2] argued that in a real situation where loops of various sizes and shapes are present, the boundaries between the different regions of stability would be diffuse, leading to a gradual transition in loop types.

This picture above is clearly in good qualitative accord with our observations. We found that $1 / 2<111>$ loops were dominant components of the microstructure at temperatures $\mathrm{T}_{\text {irr }} \leq 300^{\circ} \mathrm{C}$, although small $<100>$ loops were present even at room temperature $[3,4]$. At temperatures $\mathrm{T}_{\text {irr }} \geq 400^{\circ} \mathrm{C},<100>$ loops became increasingly important components of the microstructure (figure 7). Our observations are therefore | compatible with a picture that $<100>$ loops become more energetically favoured with increasing temperature. However the mechanism by which the transition in loop types | takes place is still not entirely clear. In particular, the abrupt disappearance of $\underline{1} 12<111>$ loops at temperatures $\mathrm{T}_{\mathrm{irr}}>465^{\circ} \mathrm{C}$ was something of a surprise. Unlike Arakawa et al $[19]$ we did not see $1 / 2<111>$ loops transform directly into $<100>$ loops. Small mobile $1 / 2<111>$ loops were produced at $\bar{T}_{\text {irr }}=465^{\circ} \mathrm{C}$, but were quickly subsumed by sessile $<100>$ loops. The crabwise motion by which the $1 / 2<111>$ loops approached the $<100>$ loop (video 6 , figure 6) evidently involved self-climb, since the sizes of the $1 / 2<111>$ loops remained unchanged at the resolution of the CCD camera. Coalescence of interstitial loops by selfclimb has been observed previously during an isothermal anneal of ion-implanted $\mathrm{UO}_{2}$ by Turnbull [20]. Turnbull considered two possible driving forces: first the mutual interaction of the loop strain fields, and second the interaction of the strain fields of loops and vacancies. He concluded that in metals both interactions were likely to be important.

Clues to the possible mechanisms underlying our observations may be gleaned from molecular dynamics simulations of displacement cascades in Fe by Bacon and co-

| workers [21]. In these simulations small, self-interstitial clusters formed at the cascade peripheries at the end of the displacement phase of the cascade in an essentially athermal $\mid$ process, or by short-range diffusion during the thermal-spike phase. Smaller clusters may be considered as bundles of $\langle 111\rangle$ or $\langle 100\rangle$ crowdions. These clusters are very mobile, even at low temperatures, moving by thermally-activated one-dimensional glide along the crowdion direction. Larger clusters of crowdions may be considered as small, but probably sub-microscopic $1 / 2<111>$ or $<100>$ dislocation loops. We surmise that loops large enough to be seen in the TEM form by the coalescence of such small clusters, and

\begin{tabular}{l} 
Deleted: a \\
Deleted: $a / 2$ \\
Deleted: $a / 2$ \\
Deleted: a \\
\hline
\end{tabular}

Deleted: a

\begin{tabular}{|l|}
\hline Deleted: $\mathrm{a} / \mathrm{2}$ \\
\hline Deleted: $\mathrm{a}$ \\
\hline Deleted: $\mathrm{a}$ \\
\hline Deleted: $\mathrm{a}$ \\
\hline Deleted: $\mathrm{a} / 2$ \\
\hline Deleted: $\mathrm{a} / 2$ \\
\hline Deleted: $\mathrm{a} / 2$ \\
\hline Deleted: $\mathrm{a}$ \\
\hline Deleted: $\mathrm{a} / 2$ \\
\hline Deleted: $\mathrm{a}$ \\
\hline Deleted: $\mathrm{a} / 2$ \\
\hline
\end{tabular}

\section{Deleted:}

Deleted: Most

Deleted: $a / 2$ 
that this process is more likely to occur in the foil interior since the surfaces act as efficient sinks. Loops with $\mathbf{b}=\langle 100>$ which reach visible size become sessile, whereas $\mathbf{b}=\underline{1} / 2<111>$ loops remain mobile. Both types continue to grow by absorbing mobile submicroscopic clusters and smaller loops, and by coalescing with loops of comparable | size. In the case of the mobile $1 / 2<111>$ loops, elastic interactions play an important role in this process. The relative proportions of the two loop types are probably determined by by a combination of factors, including their stabilities at small sizes, and the increased mobility of $1 / 2<111>$ loops at higher temperatures. At temperatures above $450^{\circ} \mathrm{C}$, small $1 / 2<111>$ loops are less likely to form, and those which do are quickly subsumed into $<100>$ loops and never reach large sizes. At temperatures higher than $500^{\circ} \mathrm{C}$ this process may occur before any microscopic $1 / 2<111>$ loops form at all, and so such loops are not seen in the high temperature regime.

A final question concerns the fate of vacancies in our experiments. We have determined the nature of larger loops using the inside-outside contrast technique, and all were found to be interstitial. Evidence presented in this paper shows that most if not all of | the mobile $1 / 2<111>$ loops are also interstitial in nature. Vacancy-rich regions are likely to form within cascades, but calculations suggest that closed vacancy loops of size $\leq 4 \mathrm{~nm}$ are not formed, while small open loops transform to voids [22,23]. We have looked for but not found small voids in pure Fe, suggesting that any present are of size below the resolution limit of $\sim 2 \mathrm{~nm}$. We did find very small voids in Fe8\% $\mathrm{Cr}$ irradiated under similar conditions [5]. It is also possible that some of the small near-surface loops might be of vacancy nature [3].

\section{Summary and conclusions}

- We have described a transition in the microstructures of pure Fe produced by heavy-ion irradiation of thin foils which took place between irradiation temperatures $\mathrm{T}_{\text {irr }}$ of $300^{\circ} \mathrm{C}$ and $500^{\circ} \mathrm{C}$.

- Our previous work had shown that for $\leq 300^{\circ} \mathrm{C}$, the microstructure was dominated by interstitial loops with Burgers vectors $\mathbf{b}=1 / 2<111>$. At $\mathrm{T}_{\text {irr }}=400^{\circ} \mathrm{C}$, about $50 \%$ of self-interstitials were still contained in $1 / 2<111>$ loops, which were frequently round or of irregular shape and had shear components. These loops were very mobile and frequently coalesced into larger loops. A high proportion of small, sessile, edge $<100>$ loops was also present, also accommodating about $50 \%$ of the interstitials.

- There was a gradual transition in microstructure at temperatures greater than $400^{\circ} \mathrm{C}$. At $\mathrm{T}_{\mathrm{irr}}=450^{\circ} \mathrm{C}$, loops with $\mathbf{b}=1 / 2<111>$ were still present, and interacted elastically to form long chains, but loops with $\mathbf{b}=<100>$ of pure edge character and rectilinear shape, now dominated in most areas, and accommodated a majority of the interstitials.

\section{Deleted: a}

Deleted: $a / 2$

Deleted: $a / 2$

\section{Deleted: a}

Deleted: s

Deleted: a/2

Deleted: a/2

Deleted:

Deleted: a/2

Deleted: a 
- At temperatures $\mathrm{T}_{\text {irr }} \geq 450^{\circ} \mathrm{C}$, small, mobile $1 / 2<111>$ loops were seen to be subsumed by sessile $<100>$ loops, and large $1 / 2<111>$ loops did not form. At $500^{\circ} \mathrm{C},<100>$ loops developed into large networks, and no visible $1 / 2<111>$ loops formed.

- A plausible explanation of these observations has been given in terms of the relative stabilities of $1 / 2<111>$ and $<100>$ loops as a function of temperature, and the possible mechanism by which the microstructure develops.
Deleted: a/2

Deleted: a/2

Deleted: a/2

\section{Acknowledgements}

We thank Dr. A. Liu and P. Baldo of Argonne National Lab for their help in using this facility. The IVEM-Tandem Facility (within the Electron Microscopy Center at ANL) is supported by the US DOE Office of Science and operated under contract no. DE-AC0206CH11357 by UChicago Argonne, LLC. We are grateful to Dr. S. L. Dudarev and Dr. S. P. Fitzgerald for helpful discussions. We thank B. Miller, D. Graham, and Prof. I M. Robertson (UIUC) for help with video 4. Part of this work was funded by the UKAEA, Culham Science Centre.

\section{References}

1. S. P. Fitzgerald and S. L. Dudarev, Proc. R. Soc. A 4642549 (2008).

2. S. L. Dudarev, R. Bullough and P. M. Derlet, Phy. Rev. Lett., 100135503 (2008).

3. Z.Yao, M. Hernandez-Mayoral, M. L. Jenkins and M.A. Kirk, Phil. Mag. 882851 (2008).

4. M. Hernandez-Mayoral, Z. Yao, M. L. Jenkins and M.A.Kirk, Phil. Mag. 882881 (2008).

5. M. L. Jenkins, Z. Yao, M. Hernandez-Mayoral and M. A. Kirk, J. Nucl. Mat. 3895 (2009).

6. D. J. H. Cockayne, I. L. F.Ray and M. J. Whelan, Phil. Mag, 201265 (1969).

7. M. L. Jenkins and M. A. Kirk (2001), Characterisation of Radiation Damage by Transmission Electron Microscopy, Institute of Physics Series in Microscopy in Materials Science (Series Editors, B Cantor and M J Goringe) ISBN 075030748 X (hbk)

8. K. Arakawa, K. Ono, M. Isshiki, K. Mimura, M. Uchikoshi and H. Mori, Science p.956, 318 (2007)

9. S. Fitzgerald and Z. Yao, Phil. Mag. Lett. (2009), in press.

10. Z. Zhou, M. L. Jenkins, S.L. Dudarev, A. Sutton and M. A. Kirk, Phil. Mag 864851 (2006).

11. C. A. English and M. L. Jenkins, Phil. Mag. (2009), in press.

12. B. C. Masters, Phil. Mag. 11881 (1965).

13. Y. Konobeev, A. Dvoriashin, S. Porollo and F. Garner, J. Nucl. Mat. 3559 (2005).

14. D. Gelles, J Nucl. Mat. 108-9 515 (1982).

15. S. Xu, Z. Yao and M.L. Jenkins, J. Nucl.Mat. (2009) in press.

16. B. L. Eyre and A. F. Bartlett, Phil. Mag. 12261 (1965).

17. M. L. Jenkins, C. A. English and B. L. Eyre, Phil. Mag. 3897 (1978). 
18. M. A. Kirk., I. M. Robertson, M. L. Jenkins, C. A. English, T. J. Black and J. S. Vetrano, J. Nucl. Mat. 14921 (1987).

19. K. Arakawa, M. Hatanaka, E. Kuramoto, K. Ono, and H. Mori, PRL 96125506 (2006)

20. J. A. Turnbull, Phil. Mag. 2183 (1970).

21. D. J. Bacon, F. Gao and Y. Osetsky, J. Nucl. Mat. 276 (2000).

22. M. R. Gilbert, S. L. Dudarev, P. M. Derlet and D. G. Pettifor, J. Phys: Condens. Matter 20345214 (2008).

23. M. R. Gilbert, Z. Yao, M. L. Jenkins and S. L. Dudarev, J. Nucl. Mat. 386-8 36 (2009). 
Figure captions

Figlie 1: $\quad$ Frames captured from video 2, showing loop coalescence in UHP Fe after irradiation at $400^{\circ} \mathrm{C}$ to $1 \times 10^{18}$ ions $\mathrm{m}^{-2}$. This occurred soon after ion irradiation ceased, as the specimen was being examined in the TEM and was still at $400^{\circ} \mathrm{C}$. Three small $1 / 2<111>$ loops towards the centre of frame A coalesce into a single $1 / 2<111>$ loop in frame $\mathrm{B}$. The loop is seen to rotate to new habit plane, frame $\overline{\mathrm{C}}$, and continues to hop.

Deleted: a/2

Deleted: $a / 2$

Figure 2: $\quad$ Contrast experiment at $\mathrm{T}_{\text {irr }}=400^{\circ} \mathrm{C}$ in UHP Fe irradiated to a dose of $2 \times 10^{18}$ ions $\mathrm{m}^{-2}(\sim 1.3 \mathrm{dpa})$ :(a) diffraction vector $\mathbf{g}=020$, so loops with $\mathbf{b}=[100]$ are out of contrast; (b) $\mathbf{g}=01 \overline{1}$ so loops with $\mathbf{b}=1 / 2[111]$ and $\mathbf{b}_{-1}=1 / 2[111]$ are out of contrast; (c) $\mathbf{g}=00 \overline{2}$, so loops with $\mathbf{b}=[010]$ are out of contrast;(d) $\mathbf{g}=01 \overline{1}$, so loops with $\mathbf{b}=1 / 2[111]$ and $\mathbf{b}=1 / 2[111]$ are out of contrast.

Chains of $1 / 2<111>$ loops are present together with a few large [001] loops and a large number of small loops of both types. In this field of view $<001>$ loops outnumber $1 / 2<111>$ loops about in a ratio of about $2: 1$.

| Figure 3: Experiment to determine the habit plane of $1 / 2[111]$ loops: (a) the specimen shown in figure 3 has been tilted close to the [310] pole. Loops with $\mathbf{b}=1 / 2[111]$ appear edge-on on, consistent with a $(\overline{1} 32)$ habit plane ; (b) and (c) show experimental images of a two loops with $\mathbf{b}=1 / 2[111]$ at the [110] and [310] poles respectively. TEMACI image simulations for a circular loop with this Burgers vector lying on (132) are inset at the lower

\begin{tabular}{l} 
Deleted: a \\
Deleted: a/2 \\
Deleted: \\
Deleted: a/2 \\
Deleted: a \\
Deleted: $\mathrm{a} / 2$ \\
\hline Deleted: $\mathrm{a} / 2$ \\
\hline Deleted: $\mathrm{a} / 2$ \\
\hline Deleted: $\mathrm{a} / \mathrm{a}$ \\
\hline Deleted: $\mathrm{a} / 2$ \\
\hline
\end{tabular}
left in each case.

Figure 4: $\quad$ Loops in UHP Fe at $450^{\circ} \mathrm{C}$ at a dose of $3 \times 10^{18}$ ions $\mathrm{m}^{-2}$ : (a) long lines of large $1 / 2<111>$ loops in a grain oriented about $20^{\circ}$ from [111]; (b) large loops of both types in an adjacent grain oriented close to [001], with $<100>$ loops in a preponderance; (c) edge-on $<100>$ loops in the same grain.

| Figure 5 Formation of $<100>$ loops in an [001] foil at $500^{\circ} \mathrm{C}$ : (a) at a dose of $3 \times 10^{18}$ ions $^{-2}(\mathrm{~b})$ the same area at a dose of $1 \times 10^{19}$ ions $\mathrm{m}^{-2}$.

Deleted: a/2

Deleted: a

Deleted: a

Figure 6 Stills extracted from video 6, showing single crystal [110] Fe under irradiation at $465^{\circ} \mathrm{C}$. The large loop at the centre of the micrograph with $\mathbf{b}=<100>$ subsumes two smaller $1 / 2<111>$ loops.

Deleted: a

Deleted: $a / 2$

Figure 7: $\quad$ Estimates of the fraction of interstitials contained in loops of the two types. The error bars do not take account of systematic errors due to loss of $1 / 2<111>$ loops to the surface.

Deleted: a/2 


\section{List of videos}

Video 1 Early-stage damage development in UHP Fe irradiated at $400^{\circ} \mathrm{C}$. Viewed at $2 \times$ real-time.

| Video 2 Coalescence of three $1 / 2<111>$ loops at $400^{\circ} \mathrm{C}$ under electron irradiation.

Deleted: $a / 2$ Viewed in real-time.

| Video 3 Elastic interaction of $1 / 2<111>$ loops to form loop chains at $400^{\circ} \mathrm{C}$ under Deleted: $a / 2$ ion irradiation. Viewed at $30 \times$ real-time.

Video 4 A tilt series reconstruction, showing large loops lie close to the foil centre.

| Video 5 Loss of large [001] loops under ion irradiation in an [001] foil at $500^{\circ} \mathrm{C}$. Viewed at $10 \times$ real-time.

Deleted:

| Video $6 \quad$ A large $<100>$ loop subsumes two small $1 / 2<111>$ loops under ion irradiation at $\overline{4} \overline{5}{ }^{\circ} \mathrm{C}$. Viewed at $2 \times$ real-time.

Deleted: a

Deleted: $a / 2$ 
1

2

3

4

5

6

7

8

9

10

11

12

13

14

15

16

17

18

19

20

21

22

23

24

25

26

27

28

29

30

31

32

33

34

35

36

37

38

39

40

41

42

43

44

45

46

47

48

49

50

51

52

53

54

55

56

57

58

59

60
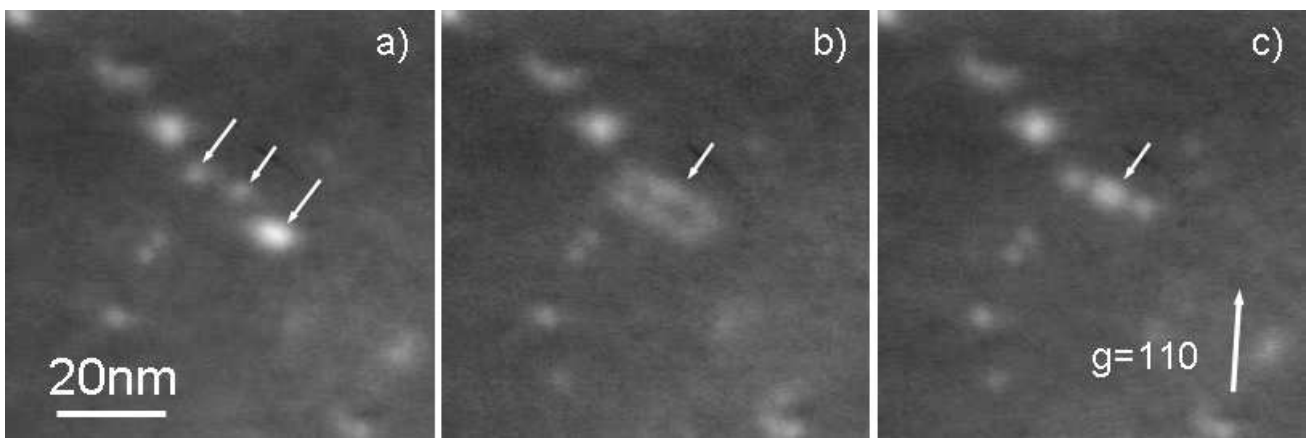

$286 \times 94 \mathrm{~mm}(72 \times 72 \mathrm{DPI})$ 

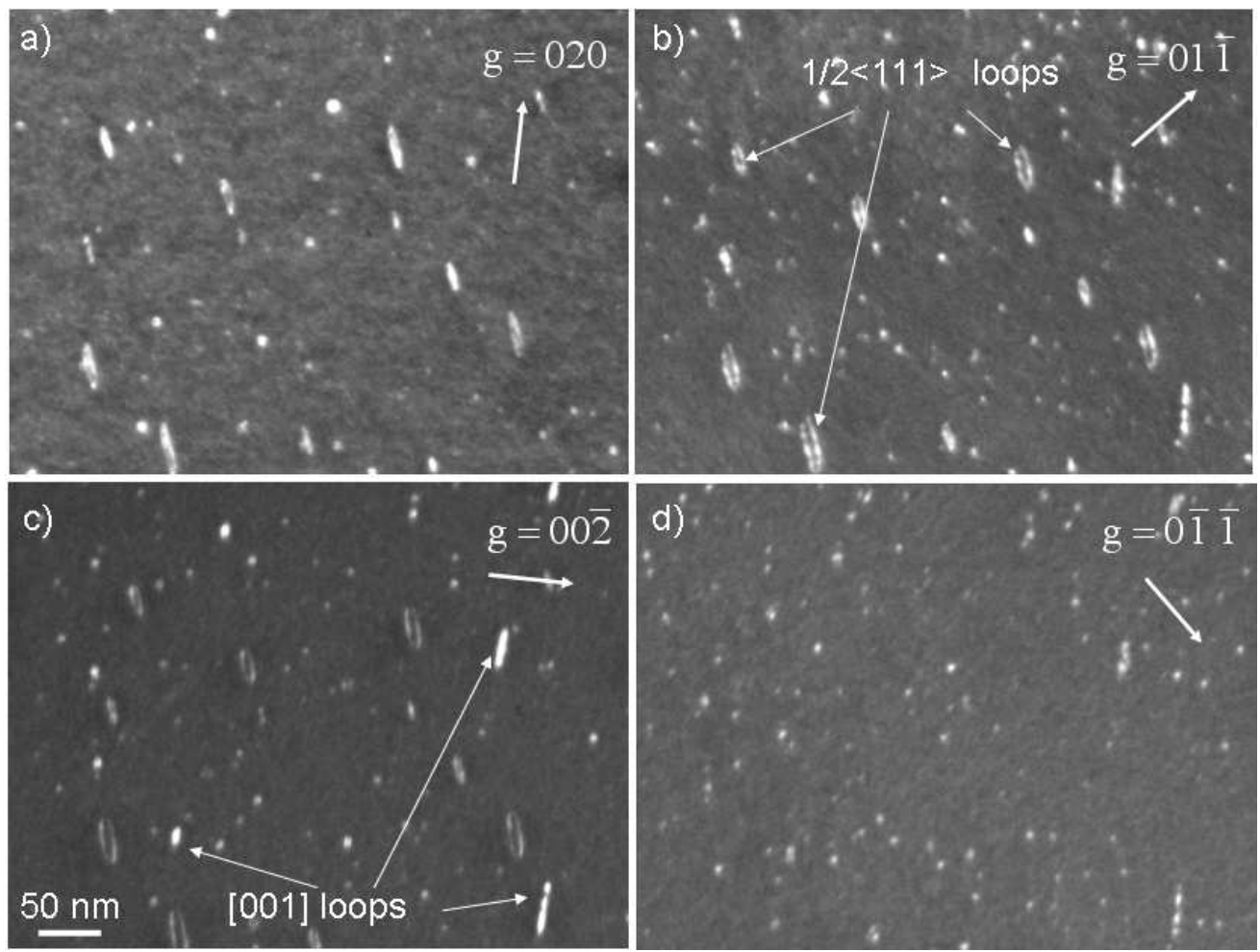

$292 \times 220 \mathrm{~mm}(72 \times 72$ DPI $)$ 

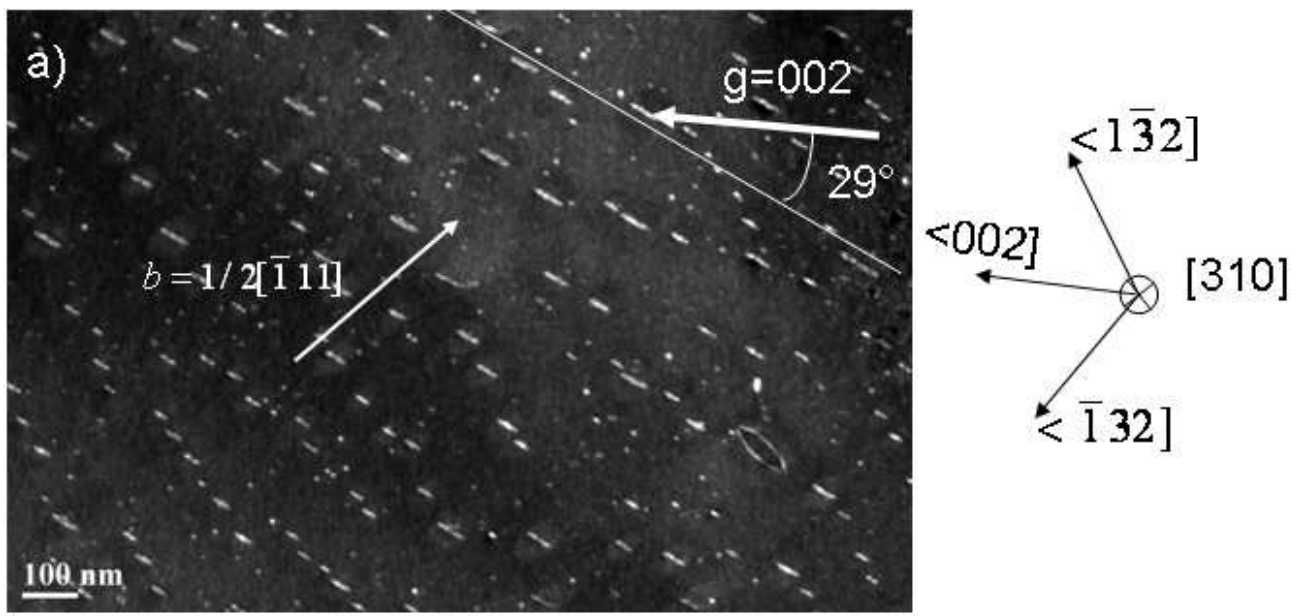

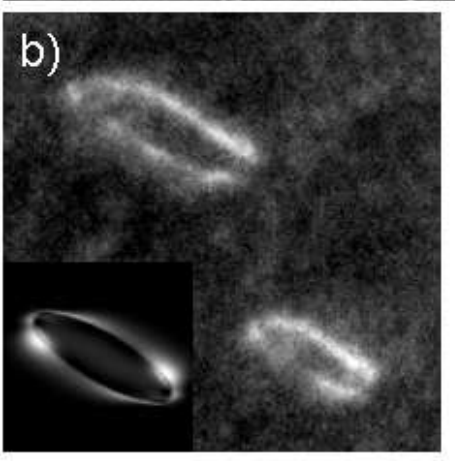

Pole [110]

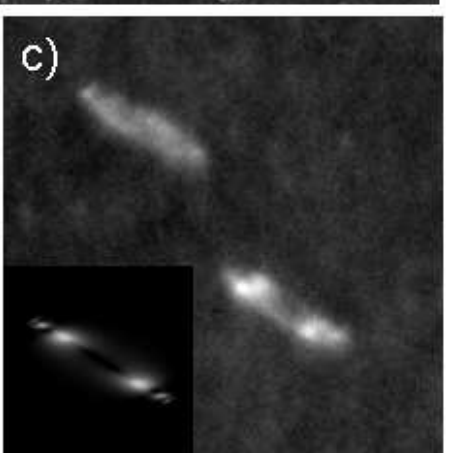

[310]

$20 \mathrm{~nm}$

$237 \times 209 \mathrm{~mm}(72 \times 72$ DPI $)$ 


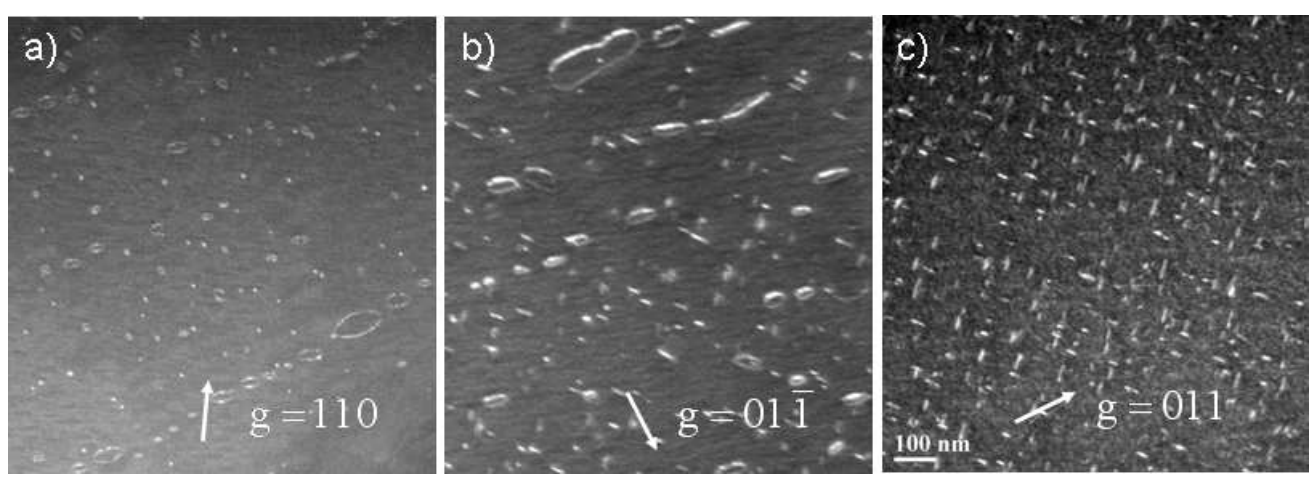

$286 \times 100 \mathrm{~mm}(72 \times 72$ DPI $)$ 


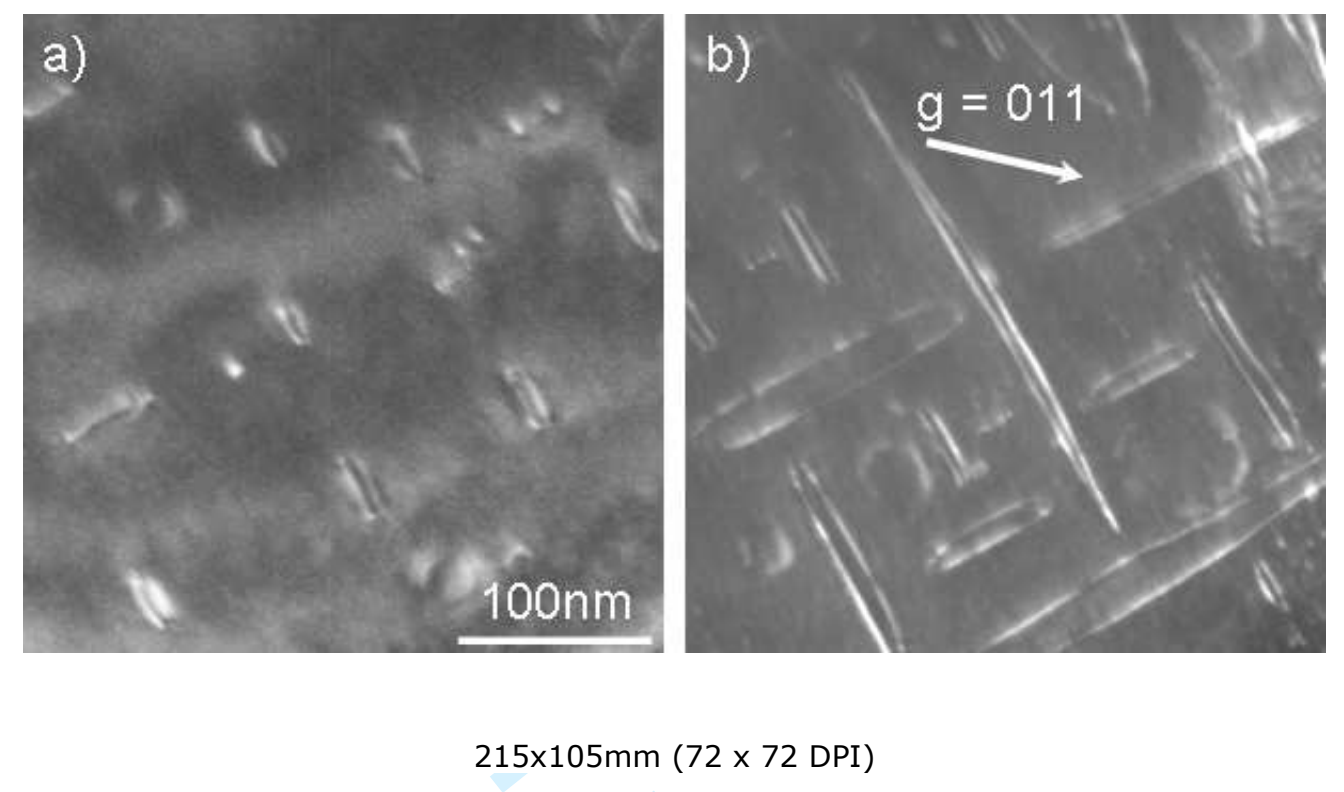

2

4

5

6

7

8

9

10

11

12

13
14

15

16

17

18

19

20

21

22

23

24

25

26

27

28

29

30

31

32

33

34

35

36

37

38

39

40

41

42

43

44

45

46

47

48

49

50

51

52

53

54

55

56

57

58

59

60

http://mc.manuscriptcentral.com/pm-pml 

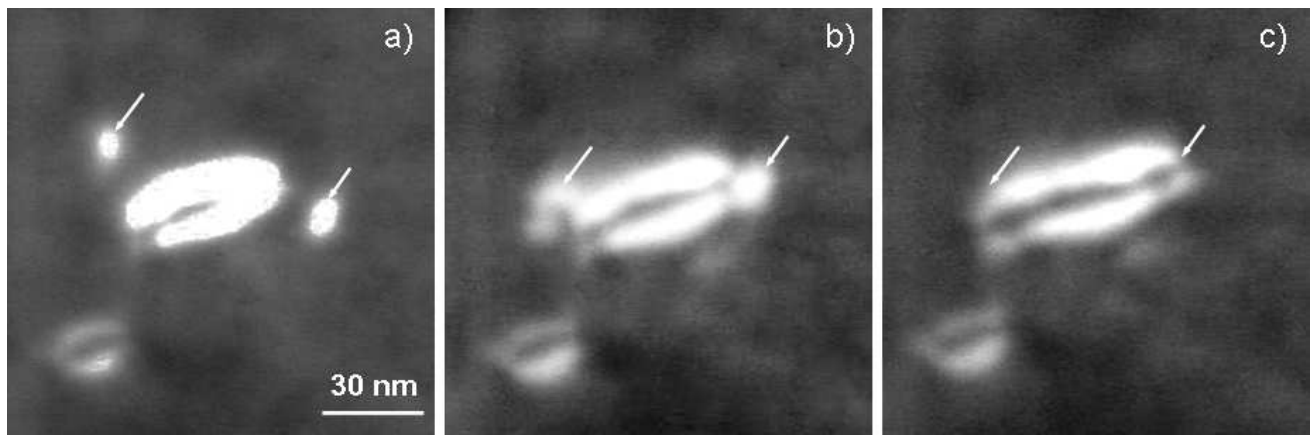

$325 \times 106 \mathrm{~mm}(72 \times 72$ DPI $)$ 


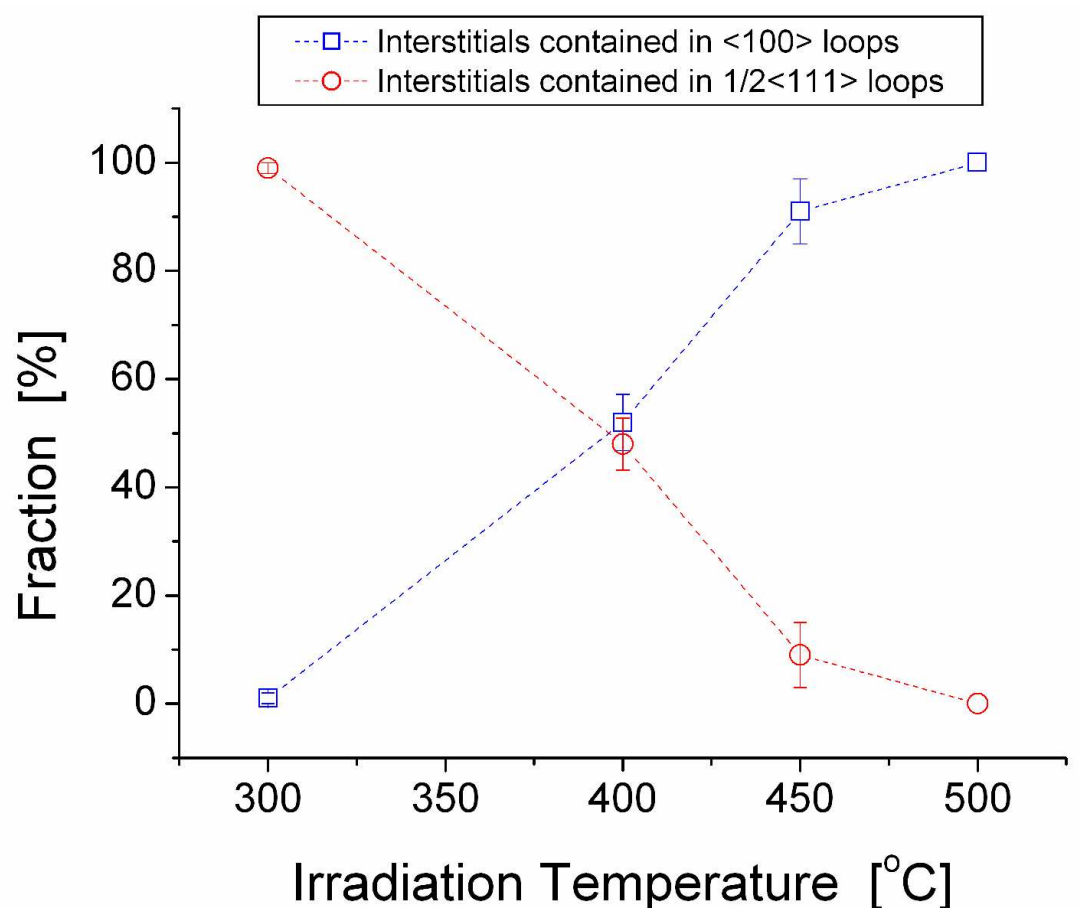

$575 \times 399 m m(150 \times 150$ DPI $)$ 